\title{
Effects of Different Content Delay Released Welan Gum Pellets on the Performance of Cement Paste
}

\author{
Chengjie $\mathrm{Qu}^{1, \text { a }}$ Qinglin Zhao ${ }^{1,2, \mathrm{~b}}$ \\ ${ }^{1}$ School of Materials Science and Engineering, Wuhan University of Technology, Wuhan 430070, \\ China; \\ ${ }^{2}$ State Key Laboratory of Silicate Materials for Architecture, Wuhan 430070, China. \\ aqcj_whut@163.com, bzhaoqinglin@whut.edu.cn,
}

Keywords: Delay release wenlan gum, Bleeding rate, Hydration heat.

Abstract. Welan gum is widely applied in environmental admixtures due to its good thickening and rheological properties. There is an obvious competitive absorption when welan gum coexists with polycarboxylate superplasticizer. Effect of different modified welan gum pellets on the properties of cement and concrete were studied in this paper. Compared with original welan gum, appropriate preparation technology and content were optimally selected.

\section{Introduction}

Welan gum is a new kind of microbial polysaccharide produced from aerobic submerged fermentation of Alcaligenes species [1,2], whose molecular structure is shown in Figure 1[3,4]. Welan gum can be used as thickener in mortar and concrete, for its good rheological property and anti-segregability. The solution's viscosity of solution increases rapidly when welan gum is dissolving. Even if the concentration is as low as $0.01 \%$, the solution's viscosity is also very high. Welan gum is also well-known for its good thermal stability when the temperature is higher than $150 \square$. And welan gum has relative stability to bivalent cation. All the excellent properties make it widely used in mortar, concrete and high temperature drilling fluid.

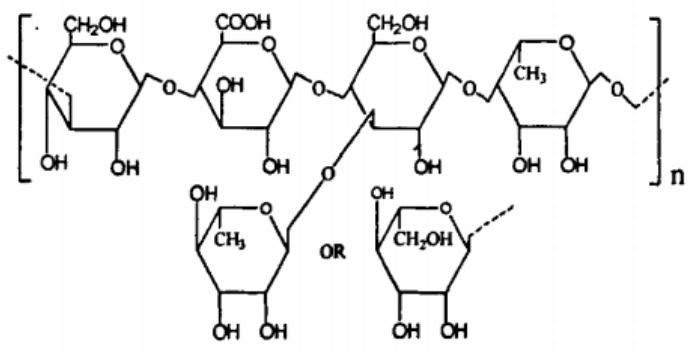

Fig. 1 Molecular structure of welan gum

While welan gum coexists with other admixture, such as polycarboxylate superplasticizer in mortar or concrete, there will be an obvious competitive absorption[5], which makes a portion of admixture lose efficacy, doing a direct harm to cement mortar's performance and increasing the cost of admixture. Three kinds of delay released welan gum pellets with different properties were prepared. In this paper, the effects of different delay released welan gum pellets on the properties of cement were studied by experiments. Compared with original welan gum, appropriate preparation technology and dosage were optimally selected. 


\section{Materials and methods}

Raw materials. Delay released welan gum (DRWG): Welan gum, produced by a company of Hebei Province, is yellow flocculent powder of small aggregate structure. There are three kinds of delay released welan gum pellets (DR-A, DR-B, DR-C) prepared by different production technology, DR-A is snowflake-like fluffy particles, DR-B round particles, and DR-C solid stick particles. Photo of welan gum and DRWG is shown in Figure 2. In accordance with different application environment and requirement, the volume of DRWG is suggested to $0.01-0.10 \%$ of the total quality of cement material. Eight different volume between $0.01 \%$ and $0.2 \%$ were selected in the experiment.

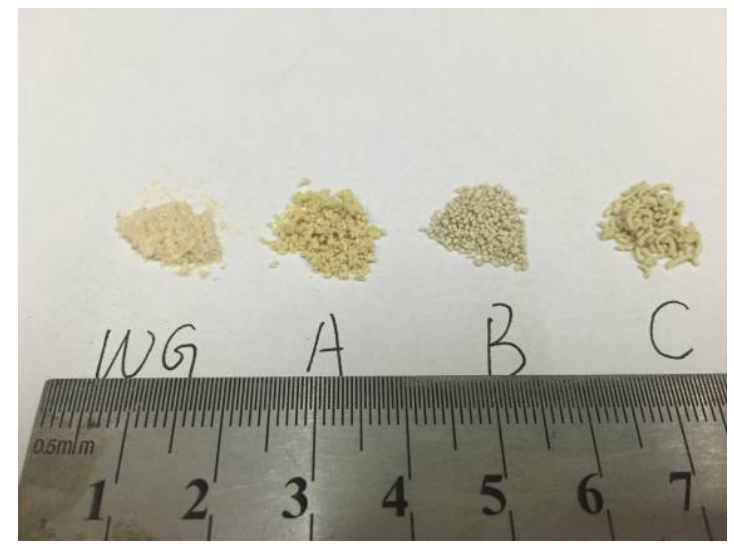

Fig. 2 Photo of welan gum and DRWG

Cement: The main binder used in this research is PO 42.5 cement, whose physical properties and chemical composition are shown in Table 1 and Table 2.

Table 1 Cement chemical composition analysis (\%)

\begin{tabular}{ccccccccc}
\hline $\begin{array}{c}\text { Chemical } \\
\text { composition }\end{array}$ & $\mathrm{CaO}$ & $\mathrm{SiO}_{2}$ & $\mathrm{Al}_{2} \mathrm{O}_{3}$ & $\mathrm{Fe}_{2} \mathrm{O}_{3}$ & $\mathrm{MgO}$ & $\mathrm{SO}_{3}$ & $\mathrm{~K}_{2} \mathrm{O}$ & Loss \\
\hline Cement & 59.19 & 22.07 & 5.94 & 3.58 & 1.40 & 2.54 & 0.87 & 3.41 \\
\hline
\end{tabular}

Table 2 Cement physical properties

\begin{tabular}{cccccccc}
\hline \multirow{2}{*}{$\begin{array}{c}\text { Consistency } \\
(\%)\end{array}$} & $\begin{array}{c}\text { Setting time } \\
(\mathrm{h}: \min )\end{array}$ & $\begin{array}{c}\text { Flexural strength } \\
(\mathrm{MPa})\end{array}$ & $\begin{array}{c}\text { Compressive strength } \\
(\mathrm{MPa})\end{array}$ & $\begin{array}{c}\text { Specific surface area } \\
\left(\mathrm{m}^{2} / \mathrm{kg}\right)\end{array}$ \\
\cline { 2 - 7 } & Initial & Final & $3 \mathrm{~d}$ & $28 \mathrm{~d}$ & $3 \mathrm{~d}$ & $28 \mathrm{~d}$ & \\
\hline 25.7 & $2: 29$ & $3: 45$ & 27.1 & 42.6 & 7.1 & 8.9 & 395.21 \\
\hline
\end{tabular}

Polycarboxylate superplasticizer (PCE): Yellow powder. The water reducing rate is $23 \%$, and the recommended dosage is $0.1 \mathrm{wt} \%$.

Test methods. Water requirement of normal consistency and setting time: The test was measured according to GB/T1346-2011. Three kinds of cement pastes were prepared according to the designed proportions with $0.1 \mathrm{wt} \%$ welan gum or DRWG.

Fluidity: Mortar fluidity was measured according to GB/T 2419-2005. Mortar mixtures were prepared by adding water, 0.1\%wt PCE and different dosage welan gum or DRWG to PO42.5 cement. The dosage of welan gum or DRWG is from $0.01 \mathrm{wt} \%$ to $0.2 \mathrm{wt} \%$.

Mechanical properties: Standard cement mortar mixtures of China Standard GB/T 17671-1999 were added with $0.1 \mathrm{wt} \%$ PCE and $0.01 \mathrm{wt} \%-0.2 \mathrm{wt} \%$ welan gum or DRWG. The strength of cement mortar was assessed after $3 \mathrm{~d}$ and $28 \mathrm{~d}$ respectively in accordance with China Standard GB/T 
17671-1999.

Standing bleeding rate of paste: To assess anti-bleeding capacity, the effect of a designed proportion of welan gum or DRWG upon cement was studied for different dosage of welan gum or DRWG. The paste was prepared with the water-cement ratios of 0.5. After being mixed, the paste was poured into $250 \mathrm{~mL}$ measuring cylinder and sealed, then kept standing for $1 \mathrm{~h}$ to observe the bleeding.

Hydration heat: Hydration heat was measured according to GB/T 12959-2008. Different-dosage DRWG and $0.1 \mathrm{wt} \%$ PCE were added into the cement of the water-cement ratio being 0.5 .

\section{Results}

Consistency and setting time. The effects of $0.1 \mathrm{wt} \%$ welan gum or DRWG on the consistency and setting time are shown in Table 3.

Table 3 DRWG effect on consistency and setting time

\begin{tabular}{cccc}
\hline & Consistency (\%) & Initial (h:min) & Final (h:min) \\
\hline Blank & 25.7 & $2: 29$ & $3: 45$ \\
WG & 27.6 & $2: 51$ & $5: 00$ \\
DR-A & 23.9 & $2: 44$ & $4: 14$ \\
DR-B & 25.2 & $2: 54$ & $4: 13$ \\
DR-C & 25.3 & $2: 51$ & $4: 18$ \\
\hline
\end{tabular}

In Table 3, the initial setting time and the final setting time increase when welan gum and DRWG are mixed into the paste. The final setting time increases from 225 mins to 300 mins with welan gum. When it is replaced by DRWG, the final setting time increases around 30 mins. Welan gum makes the water requirement of normal consistency increase, while DRWGs reduce the consistency. Welan gum is a kind of Polysaccharide that can delay cement paste hydration.

Fluidity. The effects of different dosage welan gum or DRWG and $0.1 \mathrm{wt} \%$ PCE on fluidity are shown in Figure 3.

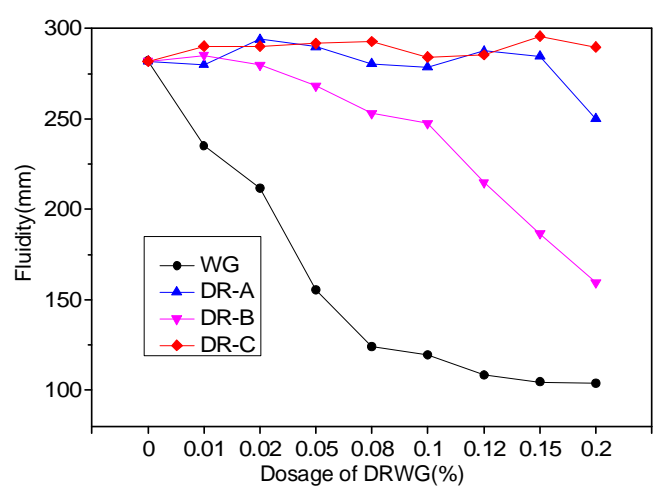

Fig. 3 effect of different dosage welan gum or DRWG on fluidity

When welan gum is mixed with mortar, the fluidity is reduced obviously. $0.01 \mathrm{wt} \%$ welan gum makes the fluidity reduce from $269 \mathrm{~mm}$ to $229 \mathrm{~mm}$. When the dosage of welan gum exceeds 0.08 $\mathrm{wt} \%$, the fluidity is as low as $122 \mathrm{~mm}$. DR-A and DR-C have little influence on the fluidity of mortar, whereas DR-B reduces the fluidity. However, the effect of DR-B is less than that of welan gum.

Strength. The effects of different dosage welan gum or DRWG and 0.1 wt\% PCE on compressive strength and flexural strength are shown in Figure 4 and Figure 5. 

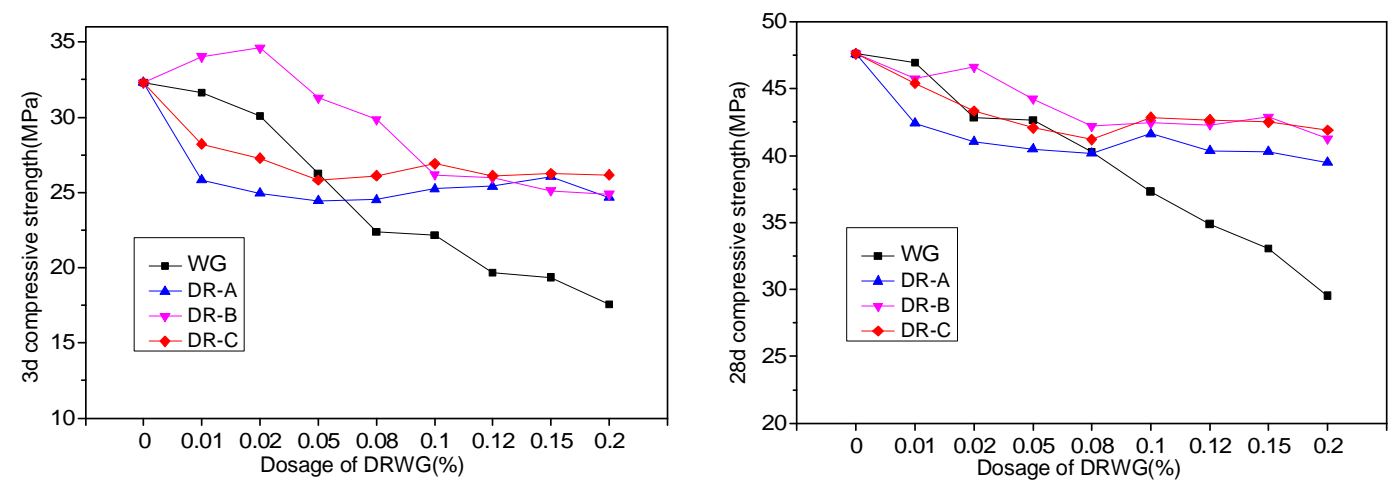

Fig. 4 Effects of different dosage DRWG on compressive strength when 3d(left) and 28d(right)
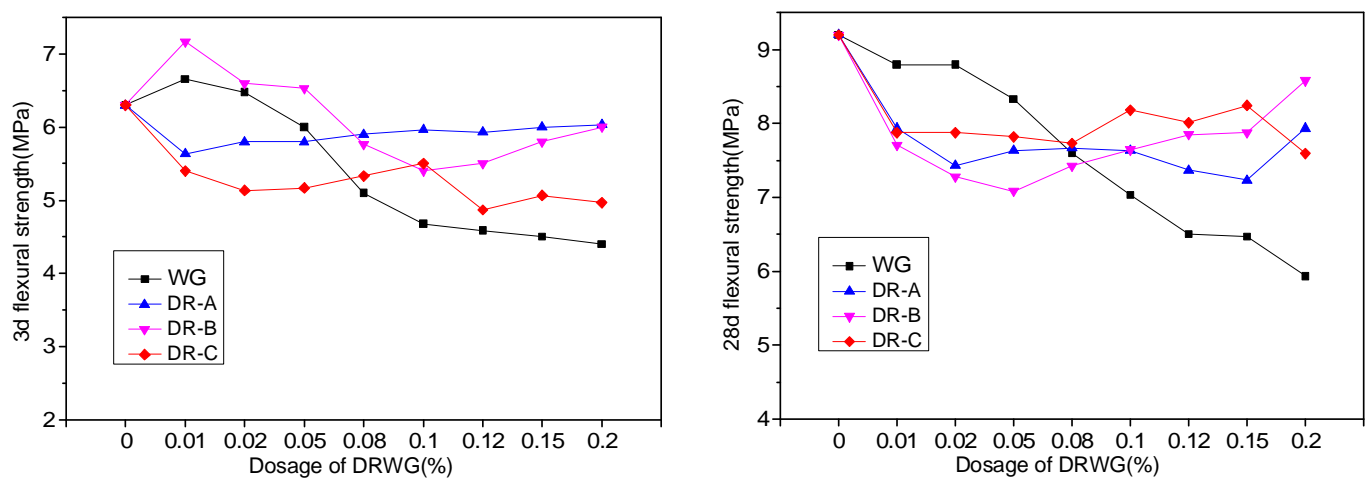

Fig. 5 Effects of different dosage DRWG on flexural strength when 3d (left) and 28d (right)

From Figure 4 and Figure 5, DRWG just slightly affects the compressive strength compared with PO42.5 cement mortar, whereas welan gum displays a substantial strength reduction by about 50\% when the dosage is $0.12 \mathrm{wt} \%-0.2 \mathrm{wt} \%$. And DR-B can slightly increase the compressive strength at the low dosage of $0.02 \mathrm{wt} \%$.

Compared with DR-A and DR-C, DR-B has less effect on motar strength and dissolves faster. And it has better anti-bleeding capacity. DR-B is the most appropriate delay released welan gum among the three different kinds of pellets.

Bleeding rate. The bleeding rate of cement paste can be used to evaluate the anti-bleeding capacity of cement paste. Table 3 shows the bleeding rates of cement paste prepared by different dosage DR-B and $0.1 \mathrm{wt} \%$ PCE. The water cement ratio is limited to 0.5. In Table 5, in the reference test with $0.1 \mathrm{wt} \%$ PCE, the bleeding rate is $4.0 \%$; when $0.01 \mathrm{wt} \%$ DR-B and PCE coexist in paste, the bleeding rate is $3.6 \%$; and when the dosage of DR-B increases, the bleeding rate is reduced from $3.6 \%$ to $0.8 \%$ obviously. DR-B can effectively improve the bleeding capacity of cement paste.

Table 3 DR-B and PCE effects on paste bleeding rate

\begin{tabular}{ccccccc}
\hline Mix proportion & $0.1 \% \mathrm{PCE}$ & $\begin{array}{c}0.1 \% \mathrm{PCE}+ \\
0.01 \% \mathrm{~B}\end{array}$ & $\begin{array}{c}0.1 \% \mathrm{PCE}+ \\
0.02 \% \mathrm{~B}\end{array}$ & $\begin{array}{c}0.1 \% \mathrm{PCE}+ \\
0.05 \% \mathrm{~B}\end{array}$ & $\begin{array}{c}0.1 \% \mathrm{PCE}+ \\
0.08 \% \mathrm{~B}\end{array}$ & $\begin{array}{c}0.1 \% \mathrm{PCE}+ \\
0.1 \% \mathrm{~B}\end{array}$ \\
\hline Bleeding rate $(\%)$ & 4.0 & 3.6 & 3.2 & 2.0 & 1.6 & 0.8 \\
\hline
\end{tabular}

Hydration heat. Figure 6 shows the heat rates of cement paste prepared by different dosage DR-B and $0.1 \mathrm{wt} \%$ PCE. The water cement ratio is limited to 0.5. The dosages of DR-B are $0.01 \mathrm{wt} \%, 0.05 \mathrm{wt} \%$ and $0.08 \mathrm{wt} \%$ respectively. 


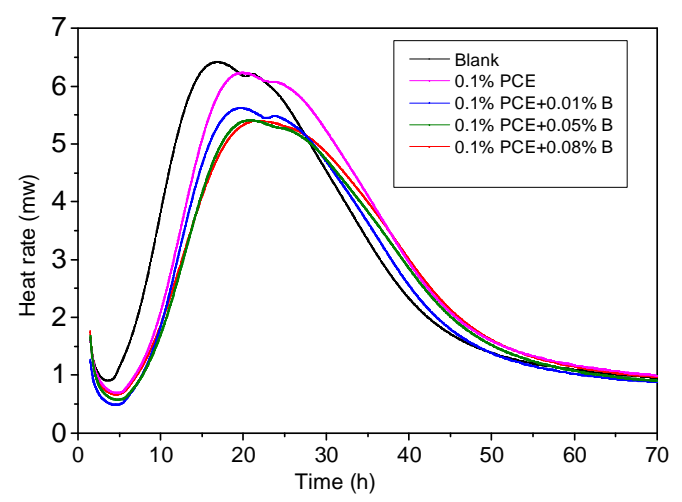

Fig. 6 Effects of different dosage DR-B on heat rate

In Figure 6 , the exothermic peak delays $4 \mathrm{~h}$ when $0.1 \mathrm{wt} \%$ polycarboxylate superplasticizer is mixed into the paste. DR-B reduces the heat rate significantly by $9.7 \%$ at the low dosage of $0.01 \mathrm{wt} \%$. While the hydration process of cement has not been affected. The paste has delayed hardening obviously when DR-B of a high dosage is mixed into.

Polycarboxylate superplasticizer can delay the induction of cement hydration and reduce the heat rate. DR-B of a low dosage has an obvious effect on the heat rate without evident delayed hardening. Monosaccharide units of welan gum can adsorb a great quantity of $\mathrm{Ca}^{2+}$ so that the induction is delayed and the paste has a delayed hardening.

\section{Conclusions}

I DR-B can increase the $3 \mathrm{~d}$ compressive strength of motar at a low dosage of $0.01 \mathrm{wt} \%$ while it has a negative effect with a high dosage. The effect of DR-A and DR-C is more than DR-B's.

I DR-B can effectively improve the bleeding of cement paste when mixed with polycarboxylate superplasticizer. The bleeding rate reduces when the dosage of DR-B increases.

I Polycarboxylate superplasticizer can reduce the heat rate. $0.01 \mathrm{wt} \%$ DR-B reduces the heat rate significantly but it has no affect to the hydration process. A high dosage of DR-B would delay the hydration process.

\section{Acknowledgments}

The research works in the paper were supported by National Natural Science Foundation of China (No. 51202173).

\section{References}

[1] Kang KS, Veeder TV. Heteropolysaccharide S-130, US patent: US 4342866; 1982

[2] Zhang Y, Zhang GP. Method for preparing a welan gum. Chinese patent: CN200610012511.0; 2006. (In Chinese)

[3] Zhao QL, Li BX. Ecological dry-mixed mortar. Beijing: Chemical industry press; 2012. (In Chinese)

[4] Plank J. Applications of biopolymers in construction engineering. In: Steinbüchel A, editor. Biopolymers, Weinheim/DE: Wiley-VCH; 2003, p. 29-95.

[5] J. Plank, C. Winter, Competitive adsorption between superplasticizer and retarder molecules on mineral binder surface, Cem. Concr. Res. 38 (2008) 599-605. 